\title{
El asunto cooperativo en Cuba. Perspectivas
}

\section{(The Cooperative Matter in Cuba. Perspectives)}

\author{
Avelino Fernández Peiso ${ }^{1}$ \\ Universidad de Cienfuegos (Cuba)
}

doi: http://dx.doi.org/10.18543/dec-15-2020pp17-34

Recibido: $10-02-2020$

Aceptado: 06-04-2020

Sumario: I. Introducción. II. La institución cooperativa. III. La cooperativa en Cuba. IV. Una legislación cooperativa. V. Consideraciones finales.

Resumen: La cooperativa en Cuba ha sufrido diversos abordajes. Hoy se mueve en un ambiente legal agropecuario y otro no agropecuario, sentados en normas legales no expresivas de su naturaleza social y aún pendiente de una Norma General de Cooperativas; asunto de suprema trascendencia para el proyecto socialista cubano del siglo XXI, en sede de que, si bien las cooperativas nacen en el capitalismo como respuesta de los desposeídos a las aberrantes formas de explotación, en el socialismo emergen por su naturaleza humanista y su capacidad de contribuir al desarrollo ético, moral, ideológico, socioeconómico y a los valores peculiares de la sociedad cubana. Para el desarrollo de esta contribución, el Estado cubano está obligado a garantizar eficiente promoción y fomento estatal. Sobre esta base, es propósito del presente trabajo incursionar en la cooperativa como institución socio/jurídica; la problemática del asunto cooperativo cubano, y en los planteos teóricos como fundamentos de su solución.

Palabras claves: institución cooperativa, legislación cooperativa cubana.

Abstract: The cooperative in Cuba has suffered various approaches. Today it moves in a legal agricultural and non-agricultural environment, sitting on non-expressive legal norms of its social nature and still pending a General Norm of Cooperatives; matter of supreme importance for the Cuban socialist project of the 21st century, based on the fact that, although cooperatives were born in capitalism as a response of the dispossessed to the aberrant forms of exploitation, in socialism they emerged due to their humanistic nature and their ability to contribute to the ethical, moral, ideological, socioeconomic development and to the peculiar values of Cuban society. For the development of this contribution, the Cuban State is obliged to guarantee efficient

1 Profesor Titular de Derecho Cooperativo, Departamento de Derecho, Universidad de Cienfuegos, Cuba. E-mail: avelino@ucf.edu.cu 
state promotion and promotion. On this basis, the purpose of this work is to venture into the cooperative as a socio / legal institution; the problematic of the Cuban cooperative matter, and in the theoretical proposals as foundations of its solution.

Keywords: cooperative institution, Cuban cooperative legislation. 


\section{Introducción}

Cuando los 28 tejedores ingleses, que abrieron las puertas de la Rochdale Society of Equitable Pioneer el 21 de diciembre de 1844, acordaron dar inicio a las operaciones de su sociedad cooperativa, materializando el sueño de constituirse en empresarios de nuevo tipo - empresarios-trabajadores- para solventar sus necesidades, no podían vaticinar que en los albores del siglo XXI más de 800 millones de personas, perseverando en la sistémica que edificaron, compondrían un sistema societario sui generis, viable para enfrentar los desafíos de la existencia humana, gestando la institución sociojurídica cooperativa.

Esta institución se ha visto en el eje de diversas polémicas y enfrentamientos filosóficos, ideológicos y políticos, desde la «izquierda»y la «derecha», transitando por diversos avatares políticos, tanto en procura de solventar la histórica contradicción capital-trabajo, humanizando la economía y su injusta lógica del capital; como la magnificada justicia social generalizada bajo la planificación centralizada y su lógica restrictiva de la libertad, probando mantener su naturaleza social, sentando las bases de relaciones socioeconómicas de ayuda mutua, solidarias y responsables y fundando las perspectivas de una forma justa de vida social, al colocar el capital al servicio de los derechos ciudadanos, acción y pensamiento afín al ideario socialista; actuares y polémicas a las cuales Cuba no ha sido ajena.

Así, desde la realidad y el Derecho, la cooperativa en Cuba ha sufrido diversos abordajes. Hoy se mueve en un ambiente legal agropecuario y otro no agropecuario, sentados en normas legales no expresivas de su naturaleza social y aún pendiente de una Norma General de Cooperativas; asunto de suprema trascendencia para el proyecto socialista cubano del siglo XXI, en sede de que, si bien las cooperativas nacen en el capitalismo como respuesta de los desposeídos a las aberrantes formas de explotación, en el socialismo emergen por su naturaleza socialista y su capacidad de contribuir al desarrollo ético, moral, ideológico, socioeconómico y a los valores peculiares de la sociedad cubana, contribución para la cual el Estado cubano está obligado a garantizar eficiente promoción y fomento estatal. ${ }^{2}$

Es propósito del presente trabajo incursionar en las siguientes proposiciones: la cooperativa como institución socio/jurídica; la problemá-

2 Promoción en las esferas de la educación cooperativa general, previa y permanente, capacitación empresarial, cultural, social, programas divulgativos, entre otras; el fomento en materia legislativa, fiscal, ayudas, supervisión y control clarificado, etcétera. 
tica del asunto cooperativo cubano y los planteos teóricos, fundamentos de su solución.

\section{La institución cooperativa}

Asumiendo el contenido del término institución, como el de instancias o comportamientos permanentes con relevancia social que regulan la conducta humana (Diccionario Jurídico DJ2K, 2000), la institución cooperativa se identifica por los siguientes componentes estructurales:
a) Una voluntad común: unión convencional de personas para ac- tuar en lo económico social, sin fines lucrativos y percibir bene- ficios justos.
b) Una forma social estable y duradera: sociedad cooperativa, autogestada, solidaria y responsable.
c) Un patrimonio: ${ }^{3}$ constituido a partir de los aportes de los socios al capital social.
d) Un fin: resolución de los problemas socioeconómicos de los so- cios y la comunidad.
e) Una organización: estructura orgánica democrática con pode- res.
f) Un procedimiento: manera convencional de actuar en la crea- ción y funcionamiento, contenida en los estatutos o reglamen- tos, apegados a la ley.

Que en conjunción dialéctica con los principios rochdalianos de 1844, distinguen sus valores societarios, personalista sui géneris: libre adhesión, control democrático, devolución o bonificación sobre las operaciones, limitado interés por el empleo del capital, neutralidad política y religiosa, ventas al contado, fomento de la enseñanza; cuales presupuestos del marco sociológico matriz de la institución jurídica cooperativa.

Es cierto que desde épocas prehistóricas las acciones cooperadas de los hombres están presentes en su actuar colectivo, pero las premisas de la institución cooperativa se encuentran en las propuestas emancipadoras de diversos pensadores (JOHN BelLeRS, 1654-1725; SAINT SIMON, 1760-1825; Robert OWEN, 1771-1856; ChARLES FOURIER, 1772-1837; WIlliam King, 1786-1865; Phillipe Buchez, 1796-1865; Hernan Schulze De-

3 Comprende el conjunto de bienes y derechos (activo) y de cargas y obligaciones (pasivo), susceptibles de apreciación pecuniaria. 
LITZCH, 1808-1883; LOUIS BLANC, 1812-1882; FRIEDRICH WILHEM RAIFFEISEN, 1818-1888; CHARLES GIDE, 1847-1932) y movimientos sociales, basados en la necesidad de la ayuda mutua, los sentimientos de solidaridad y de una vida digna para el ser humano.

Ahora bien, sus antecedentes más inmediatos se ubican durante la Revolución Industrial, cuando la explotación extrema del trabajo se convirtió en fuente de riqueza y explotación, que los desposeídos enfrentaron mediante dos formas asociativas: el sindicalismo y el cooperativismo. El primero, dentro de los cánones del salario y sus políticas; el segundo, a través de la autoorganización y autogestión socioempresarial.

Sus pilares teóricos estuvieron en la actividad de OWEN y KING en Inglaterra, Fourier en Francia, RAIFFEISEN en Alemania, que sistematizaron principios y concepciones para brindarles esperanza de vida humanizada a los explotados, mediante acciones autoemancipadoras, democráticas, educativas y de transformación económico social, sin quebranto de las bases del capitalismo.

Diversos ejercicios cooperativos se realizaron a lo largo de la Europa del siglo XIX, pero su materialización y sistematización comienza cuando, el 21 de diciembre de 1844, 28 pioneros asociados comenzaron a operar su Rochdale Society of Equitable Pioneers. La tendencia ha fructificado y hoy se agrupan, con sus particularidades (PIÑEIRO, 2011), en sociedades cooperativas más de 900 millones de personas en el mundo, dedicadas a variadas actividades económicas, constituyendo un modelo inconfundible de asociación de personas que operan bajo principios que le confieren identidad como institución sociológica: adhesión voluntaria y abierta; gestión democrática; participación económica de los socios; autonomía e independencia; educación, formación e información; cooperación entre cooperativas; interés por la comunidad (ACl, 1995).

En lo que a su ordenamiento legal respecta, ha cursado desde el desinterés, la identificación y el reconocimiento legal, tendiendo inclinarlas hacia la mercantilidad o la disciplina estatal subordinada (PIÑEIRO, 2011). En la actualidad, la generalidad de los países dispone de marcos legales tendentes a potenciarlas, con signos de presupuestos legales que las hacen vulnerables (NARANJo, 2003) pese, o por, ser evidente que constituyen un «factor indispensable en el desarrollo económico social» (AsAmblea General de la ONU, 1994), restando primacía al entarimado del asociacionismo mercantil o civil enraizado.

De esta suerte, en lo internacional sus planos real, conceptual y legal han sistematizado y afirmado el fenómeno cooperativo, cual sujeto económico social sui géneris y los estados se han visto compelidos (FERNÁNDEZ PeIso, 2005) a dotarlas de marcos legales poseedores de los atri- 
butos, generalmente aceptados, que su naturaleza social le otorga y las hacen diferenciables del resto de los sujetos que operan en las economías capitalistas.

También del ejercicio cooperativo se ocupó el pensamiento dialéctico materialista de Marx y Engels (MARX, 1980; ENGELS, 1982), como resultado de sus percepciones teórico prácticas del hacer político y la lucha de clases; cuestión en la que luego Lenin profundizó con novísima visión dialéctica materialista, dada la impronta de la práctica sociopolítica en la construcción socialista, al sustentar la responsabilidad del poder, donde no solo venía obligado al discurso sobre sus pasiones, sino impuesto a la praxis social de hacer caminos a partir del hecho cierto del ejercicio político, por el cual había enfrentado a todos en busca del desarrollo de su sociedad, el bienestar de su pueblo, la constatación de sus doctrinas, la materialización de sus sueños. Sueños infortunadamente truncados por los nefastos efectos de las concepciones del socialismo estatal (PIÑEIRO, 2012) y el dirigismo.

En resumen, si Marx y Engels reconocieron dos patrones de propiedad social: la estatal y la cooperativa, cada cual con su naturaleza, formas y contenidos; Lenin rebasó tal concepción al determinar que la naturaleza social de la cooperativa y válida para socialismo, consiste en la confluencia de la libertad e independencia individual y colectiva en un proceso natural de cooperación, surgido de abajo hacia arriba mediante la unión de los intereses ciudadanos, no condicionados por imperativos administrativos estatales, integrando la sistémica propia de la cooperativa a la red compuesta por el resto de los sujetos de la economía y de la sociedad. ${ }^{4}$

Así, la institución cooperativa, nacida del pensamiento socialista utópico ante la necesidad de enfrentar la explotación del capital por vías empresariales, creció como forma socioeconómica para el mejoramiento humano y se consolidó como empresa societaria de futuro, fortificando su naturaleza socialista; dada en el orden teórico por los principios de mutualidad, solidaridad, democracia, colectividad; y en el orden práctico, por la actividad personal de sus integrantes que convienen y se responsabilizan en desempeñar la doble cualidad de trabajador o receptor del servicio percibiendo por ello un rendimiento o beneficio justo y de empresario responsable por sus actos.

De tal modo ocurre que la cooperativa es una institución societaria especial en virtud de sus rasgos sociológicos y jurídicos. Los primeros,

${ }^{4}$ Al respecto acota FIGUeROA (1994: 90) que «...para Lenin la cooperación a escala de toda la sociedad y con medios modernos de producción significaba socialismo». 
por integrar una asociación humana en forma de empresa, destinada a fines socioeconómicos propios y comunitarios acordados sin intereses lucrativos; constituyen una sociedad de personas que precia el trabajo, la autogestión, la independencia, la solidaridad, la democracia y la responsabilidad.

Los jurídicos, edificados bajo la arquitectura normativa -intra y extra societaria - necesaria y suficiente para que se reconozca, actúe y asuma las consecuencias de sus actos cual persona jurídica responsable, administradora y garante del empleo efectivo del patrimonio de sus socios.

De esta manera, la cooperativa es una institución societaria personalista de singular naturaleza socialista, que se soporta y educa a los individuos en los valores distributivos (autoayuda, autogestión, autorresponsabilidad, democracia, proyección y ocupación comunitaria) y éticos (honestidad, igualdad, equidad, solidaridad, transparencia y responsabilidad social).

\section{La cooperativa en Cuba}

El cooperativismo en Cuba no tuvo arraigo social, ni trascendencia legal antes de 1959; en lo político revolucionario estuvieron las referencias programáticas guiteristas (CABRERA, 1977) y el punto de vista de la Historia me Absolverá (CASTRO Ruz, 1969). En lo económico, su presencia fue de efímera vida e influencia: unas veces empleada por reducidos sectores marginados económicamente a manera de sobrevivencia; 5 y otras, por algunos grupos de poder económico influyentes, cual proceder de enriquecimiento en virtud de las prebendas de los gobiernos y sus prácticas corruptas lucrativas (Ley Decreto 1577/54 de 4 de agosto de 1954, Tercer Por Cuanto; Fernández, 2005: 33).

En lo legal, perduraron las secuelas del traslado de las instituciones jurídicas españolas y las disposiciones administrativas dictadas durante la República.

Tal estado de cosas impedía la gestación de cultura y desarrollo de la educación cooperativa; era resultado de la dependencia económica, la influencia cultural y el destino geopolítico a que estaba sometida Cuba como neocolonia norteamericana.

5 Cinco cooperativas de la antigua región de Cienfuegos, fundadas en la década de los 50, arrojan un promedio de existencia formalizada de cuatro años (Archivo Histórico de Cienfuegos, Datos tomados de los Registros conservados). 
Desde 1959, con el proceso revolucionario y consolidación de la economía estatal hasta hoy, la opción cooperativa ha transitado por cuatro momentos fundamentales, generados por sus propias condicionantes, percepciones y reacciones de políticas económicas: ${ }^{6}$ primero, el accionar estatal del Gobierno Revolucionario fomentando cooperativas, aplicado de modo acrítico en los latifundios cañeros intervenidos por la Ley de Reforma Agraria; surgieron también asociaciones de campesinos beneficiarios de esa Ley, cual germen de las Cooperativas de Créditos y Servicios (CCS). Luego, en los años 70, las políticas tendieron a la centralización campesina inclinándola a formas paraestatales de gestión, creándose las cooperativas de producción agropecuaria (CPA). Ambas bajo el signo administrativo patrimonial, importado del extinto socialismo estatal y ajeno a su naturaleza social asociativa; no obstante, respetando la voluntariedad campesina.

Tercero, en los años 90, llegada la debacle del campo socialista europeo, la voluntad política del Partido Comunista se inclina a desmembrar la gran propiedad estatal sobre tierra y bienes, disponiendo la creación de las Unidades Básicas de Producción Cooperativas (UBPC),

${ }^{6}$ Cada momento, sin solución de continuidad, se ha generado por propias coyunturas políticas, económicas, socioclasistas y epocales: el primero, la naciente Revolución sufría, tanto por el depauperado estado socioeconómico existente, como por los nuevos enfrentamientos y agresiones norteamericanas y la contrarrevolución interna, además de la premura por cumplir su programa, la necesidad imprescindible de elevar el nivel de vida y adhesión revolucionaria de las capas más necesitadas de la sociedad, brindando opciones laborales, educativas, de salud, etcétera. La segunda, en franca inclinación hacia el socialismo real y la planificación centralizada se trasladan, de forma acrítica, modelos inoperantes de la gestión económica estatal hacia el sector campesino, entre ellos el modelo administrativo patrimonial no asociativo de las cooperativas, interesando acercarlas a formas estales de gestión. La tercera, apremiada por las drásticas condicionantes que la debacle del socialismo europeo dejó a Cuba, se procede a desmembrar la gran propiedad estatal agraria inoperante, buscando formas de producción agropecuaria menos gravosas, no requeridas de la dependencia de alta densidad tecnológica y sin mengua del contenido administrativo patrimonial estatal, con otro cambio formal no conceptual, bajo semejante paradigma centralizante que las anteriores cooperativas. La cuarta, ante la precariedad del empleo y salario estatal, las inversiones extranjeras, la masificación del empleo privado formal e informal, la movilidad de obreros, profesionales y otros trabajadores hacia el empleo privado, en especial en los sectores terciario y cuaternarios; las TIC, su masificación e influencia; las aperturas imprescindibles al mundo con el incremento de los intercambios personales, profesionales e institucionales, se provocaron profundos cambios de la estructura socioclasista con repercusiones ideológicas que determinaron lo que se ha llamado "actualización del modelo económico», en el cual se incluye la admisión de las cooperativas no agropecuarias a forma de administrar, centralizar y legalizar opciones colectivas de autoempleo urbano, que contribuyeran a descongestionar cargas estatales en actividades gastronómicas, de servicios y otras prestaciones por privados. 
bajo semejante paradigma administrativo patrimonial y no societario de las anteriores.

El cuarto ocurre en el 2011 como parte de la actualización del modelo económico cubano que, en el VI Congreso del Partido, fijó en los Lineamientos 25 al 29 (VI Congreso del PARTIDo Comunista de CuBA, 2011) la creación de cooperativas en diferentes sectores no agropecuarios de la economía, dirigido a descongestionar al Estado del peso de prestaciones a la población, legalizando y centralizando la opción asociativa de actores privados; con ellas se introdujo en el ambiente cooperativo nacional ${ }^{7}$ distintas modalidades de cooperativas con percepción asociativa; diversas titularidades sobre los bienes que emplearen; variadas formas de empleo y gestión de esos bienes; y un complejo proceso de autorización estatal.

En la matización jurídica de los ambientes cooperativos nacionales, agropecuario y no agropecuario, el ordenamiento legal se constituye por normas propiamente cooperativas y normas incidentalmente cooperativas, las que a su vez provienen de diversas fuentes y normas de desarrollo y reglamentario.

En lo Agropecuario, las CCS y CPA, poseen en el art. 20 de la Constitución su fuente constitucional y en la vigente Ley no. 95/02,8 «Ley de Cooperativas de Producción Agropecuarias y de Créditos y Servicios», la de desarrollo. Los art. 15 y 17 de la Constitución se declaran fuentes constitucionales de las UBPC en el Decreto Ley no. 142/93, "Sobre las Unidades Básicas de Producción Cooperativa», que las crea y dirige a resoluciones ministeriales (del Azúcar y de la Agricultura) su reglamentación, que actualmente obra en la Resolución no. 574/12 del Ministro de la Agricultura.

7 El ambiente cooperativo nacional se constituye por varios modelos sociojurídicos, marcados por su forma organizacional y de actuación económica y social diferente del resto de los sujetos estatales, mixtos o privados que operan en la economía nacional; se caracterizado por integrarse en tres modalidades cooperativas dirigidas a la producción y servicios en el sector agropecuario y varias en el no agropecuario; se asientan en propios sistemas constitutivos y niveles de autorización estatal; despliegan específicas relaciones entre sus integrantes; gozan de un modo especial de practicar las relaciones laborales, disciplinarias, de seguridad social y de sustanciación de los conflictos internos; disfrutan de cierta flexibilidad en su régimen económico; apuntan a particulares vínculos con las autoridades estatales, entidades económicas y organizaciones políticas, sociales y de masas; exhiben formal autonomía del Estado; y están dotados de marcos legales propios, si bien dispersos e incoherentes.

8 Que derogó la Ley n. ${ }^{\circ} 36$, Ley de Cooperativas Agropecuarias de 22 de julio de 1982. 
En lo no agropecuario se aborda la cuestión de la fuente, acudiendo al Código Civil, ${ }^{9}$ tiene en el Decreto Ley no. 305/12, "De las Cooperativas No Agropecuarias» su norma de desarrollo y en el Decreto 309/12, la reglamentaria.

Más que carencia de unicidad en la ordenación de la institución cooperativa, mostrado con el disperso ambiente legal cooperativo, se evidencia en ellas la concepción contrapuesta del legislador al asociacionismo cooperativo, en sede las identifica y caracteriza conforme a la posición del sujeto cooperativo ante el elemento patrimonial que la sustente: propietaria, usufructuaria, arrendadora, etcétera; y por razón geográfica, conforme se desarrolle su actividad en zonas rurales (cooperativas agropecuarias), o en zonas urbanas (cooperativas no agropecuarias).

Así, en lo agropecuario se identifican las CPA como entidades económicas propietarias de tierras y otros bienes (Ley no. 95/02, art. 4.); las CCS, cuales asociaciones voluntarias de agricultores pequeños, propietarios o usufructuarios de tierras y bienes (Ley no. 95/02, art. 5); y la UBPC, organización económica social, usufructuaria de las tierras y propietaria de otros bienes (Res. no. 574/12, art. 1). Mientras en el no agropecuario, las CNA, son organizaciones con fines económicos sociales (Decreto Ley no. 305/12, art 2.1).

En síntesis, si antes de la Revolución el cooperativismo fue carente en presencia, actuares y cultura cooperativa; posterior a 1959 comenzó a fundarse el ambiente cooperativo nacional, compuesto hoy con sujetos actuantes en el ámbito agropecuario y en lo no agropecuario; es perceptible la carencia de programas de educación cooperativa; ${ }^{10}$ las normas legales en que se sustenta son dispersas, no estructuradas y ajenas a la naturaleza social/asociativa de las cooperativas.

\section{Una legislación cooperativa}

Cuatro percepciones acompañan al ambiente cooperativo nacional; la primera, difieren por su surgimiento en el capitalismo, pues no son resultado de las luchas y reclamos sociales frente a la aberrante explotación y contradicciones clasistas, ${ }^{11}$ si no por accionar estatal, frente a

9 Ante la carencia de fuente constitucional que sustentara las CNA, el legislador interpreta y asume el Código Civil como su fuente, promulgando el Decreto Ley 305/12.

10 En solitario, el art. 7 de la Ley 95/02 posee mención a ello.

11 Las normas legales en que se sustentan, son resultado de esas propias luchas, cuales «derechos arrancados» Fernández Peiso, 2006. 
carencias estructurales, de gestión y coyunturas políticas, económicas o sociales; segunda, se les diseña cual modelo administrativo patrimonial, no asociativo, ajeno a su naturaleza social; tercero, no están precedidas de procesos educativos, ni cultura social cooperativa; por último, si bien instituidas legalmente, sus normas son dispersas, no estructuradas y ajenas a la naturaleza social de las cooperativas.

El significado, contenido y consecuencias que posee el accionar estatal como fuente generadora del cooperativismo cubano, puede tener diversas lecturas (pesimistas, conformistas, optimistas, etcétera), más una lectura realista acrecienta las oportunidades de soluciones a la luz del contexto actual de la sociedad cubana; ¿pudo ser de otra manera?, pura especulación.

Por ello es de reconocer que, en lo agropecuario, el accionar estatal para el proceder cooperativo contribuyó a la elevación del nivel de vida, cultural y la conciencia revolucionaria del campesinado cubano en esos primeros años difíciles de la Revolución; luego a compensar efectos del desabastecimiento alimentario en los años duros del período especial; y que hoy la existencia de la CNA, favorece la ampliación de sus escenarios existenciales, investigaciones y espacios académicos y científicos sobre el fenómeno cooperativo.

Así, el contexto actual de la sociedad cubana exige del Estado tanto una norma general de cooperativas, como un serio proceso de educación cooperativa, so peligro de desvirtuación.

La educación cooperativa, posee dos proyecciones directas; la una hacia la cooperativa, elevando en los socios su conciencia social y valores, creciendo en lo personal y social cooperativo, su proyección comunitaria y responsabilidad social; la otra hacia la comunidad, en la que se refleja la conducta del socio y de la cooperativa, con su práctica laboral no lucrativa, transparente y éticamente correcta, representando en la comunidad los valores identificativos del grupo humano cooperativo.

Propugnar que el Estado dote a la sociedad cubana de un proceso educativo y una legislación cooperativa totalizadora, no es solo aspirar a actos intangibles, de mejoramiento formal, elevación cultural, sino a actos tangibles, como el completamiento del accionar del Estado socialista en la creación de ellas. La educación cooperativa no es un gasto más del proceso humano; es una inversión para perfeccionar, engrandecer y ascender ese proceso; con ella se perfeccionan los que la reciben a través de la transmisión y aprendizaje de los procesos tecnológicos, culturales y de comportamiento personal, societario y medioambiental; con ello el ser humano alcanza maduración y plenitud, o al menos aprende y aprehende las metas y métodos para lograrlas. 
Mientras, una adecuada legislación promueve que el desempeño empresarial cooperativo se sustente en valores de autoayuda, autorresponsabilidad, democracia, igualdad, equidad, solidaridad y proyección comunitaria; sus socios laboran y se educan —educación continuaen los de honestidad, apertura, responsabilidad personal y preocupación por los demás.

Y es así, por lo imprescindible de la adecuación legal para que el acto cooperativo se perfeccione, se refleje y actúe en los planos económico y sociales, en la naturaleza, la sociedad y el pensamiento, derivando beneficio efectivo para todos - los socios, la comunidad y el Estado - en virtud a la racional interconexión en el mercado, la intercooperación, la eliminación o minoración del intermediario sea estatal, mercantil o individual, formal o informal y su carga burocrática o lucrativa; en especial teniendo en cuenta las posibles evoluciones o involuciones de la estructura socioclasista actual que genera el contexto existencial cubano de hoy.

Dada cuenta de que en la concepción cooperativa, los preceptos del trabajo directamente cooperado exigen un contenido claramente diferenciado, más allá de la simple ejecución de operaciones cooperadas. Las operaciones cooperadas son imprescindible para la realización de cualquier actividad empresarial, sea estatal o mercantil y también se emplean para el trabajado individual o a través de la ayuda familiar o ajena - formal o informal- Es decir que las actividades cooperadas se materializan en todos los procesos de producción, de servicios o de intermediación.

Por ello es determinante discernir que, aun cuando y como organizaciones de la gestión económica deben actuar sobre la base de la eficiencia y el mercado racional -no del consumismo, no de la carencia-y, en correspondencia con sus reglas, ser competitivas y rentables, como premisa que proporciona el sustento material para el desarrollo del programa social socialista, su carácter mutualista, autogestado y responsable no puede identificarse ni con el objetivo de servir al bien público general, como en las empresas estatales; ni con el de lucrar, cual ocurre en las empresas mercantiles, incluyendo las mixtas; ni con el beneficio personal, resultante del trabajo privado individual o colectivo, formal o informal.

Diferencias que sustentan su cualidad societaria sui géneris en el orden empresarial.

Para la empresa cooperativa actuar sin fines lucrativos, en democracia y solidaridad es condición natural, lo que no es casual pues la actuación (laboral y/o de servicios empresariales) diligente en la solución de sus asuntos socio económicos, a través de la eficiencia y responsabi- 
lidad personal y de la institución, significa un medio de valorización del trabajo o del servicio; elevar la capacidad adquisitiva y la satisfacción de las necesidades materiales y espirituales; con ello se fortalece la valía cooperativa en los planos ideológicos, morales, éticos.

En tal sentido la gestión está en función de la unidad de las personas, ya que es una empresa personalista de servicios, integradora de la economía y la actividad de los socios y los excedentes que obtiene no pertenecen a la cooperativa, sino a los socios al servicio de la sociedad, es decir, no comparte ni la explotación del hombre por el hombre, ni del hombre por las instituciones.

Componente empresarial que se corona con los valores originarios que permiten darle el significado que la naturaleza socialista y la misión solidaria de la cooperativa entraña y que no están presentes en el resto de las formas económicas.

Por lo que considerando los acontecimientos reales y legales que informan el panorama económico y la estructura social contemporánea, solo la cooperativización inserta en una expresión jurídica suprema y totalizadora avenida ala naturaleza social de la cooperativa, constituye un mecanismo provechoso que contribuirá al desarrollo y la prosperidad del país, a la par de intervenir cual factor ideológico y educativo para objetivar la permanencia de la conciencia socialista de la sociedad cubana.

De esta suerte, la norma que erija la institución jurídica cooperativa nacional debe inscribir su naturaleza sociológica, como expresión de la voluntad del legislador, basada en la concepción dialéctica materialista de reconocer la institución cooperativa, como empresa formal y materialmente privada, autónoma y responsable, preservada por ley de su desvirtuación hacia el estatismo o la mercantilización; norma que brinde seguridad jurídica del alcance y equilibrio en las relaciones del poder estatal con la cooperativa y el ejercicio de las funciones estatales asesoras, controladoras y calificadoras, significando un acontecimiento legal de suma trascendencia política, económica y socioideológica.

Dictar esa norma entraña manifestar la voluntad política del servicio estatal real hacia la sociedad, en un proceso de formulación jurídica que conjugue la naturaleza, contenido y fines de la cooperativa, la racionalidad lingüística, el contexto social y los altos intereses del país.

El nuevo ordenamiento legal cooperativo, exige un diseño adecuado, encaminado a integrar los valores y principios sociales, económicos y políticos del país con los componentes esenciales de la institución cooperativa de manera armónica y racional, identificando la naturaleza, contenido, alcance y funciones económicas y sociales de las cooperativas en el socialismo. 
Si en los años 90 la crisis económica del país fue aguda, develando muchas cosas, en lo fundamental el destape de variadas percepciones sobre el quehacer para la necesaria pervivencia personal y familiar, su tendencia fue en el orden material, acompañada de cierta progresión en el deterioro de valores -éticos, morales, ideológicos-. A contrario sensu, sin excluir su contenido económico, ${ }^{12}$ los años actuales se caracterizan por el factor psicológico, en que la crisis de valores y su influencia en las relaciones materiales generadas por las inciertas perspectivas de mejoramiento material/personal fundadas en las nada pacíficas relaciones de producción e intercambio que mezclan elementos socialistas y del mercado.

Crisis de valores que se manifiesta, entre otros, por las expectativas de resolución de los proyectos personales y elevación del nivel de la vida; en el creciente escepticismo, apatía, afán de lucro, individualismo, tolerancia ante las manifestaciones de corrupción; falta de comunicación entre las personas y las instituciones estatales; formulismos en los sistemas educativos, de salud, de gobierno; desconexión entre el discurso oficial y el comportamiento moral efectivo (doble moral), que provocan sino rechazo, al menos apatía o indiferencia político ideológica.

Crisis esta, que las políticas acríticas en la autorización de modalidades de trabajo, prestaciones y servicios privados, colectivos o individuales, formales o no formales, sin adecuadas regulaciones legales, tienden a acrecentar con nefastas consecuencias ideológicas, morales y éticas que lastran y, en ocasiones, rompen el equilibrio racional necesario para la conservación y desarrollo de una sociedad proyectada al socialismo, en el discurso oficial.

Situación compleja que aún no encamina el rumbo adecuado para reestructurar, a la par que las economías —estatal, privadas, mixtas-, sus relaciones de producción, intercambio y distribución de los bienes y el patrimonio material o inmaterial, mediante expresiones legales precisas y preciosas (FERnÁNDEZ BuLTÉ, 1999: 110-111), ajenas a las tendencias coyunturales, economicistas y reduccionistas aún empleadas por el legislador y decisor.

Las expresiones legales constituyen, más que instrumentos del cambio legal, instrumentos para el cambio social; ellas, de conformidad a su modo de expresión pueden contribuir a enmascarar lacras involutivas de los procesos sociales, al ser reflejos de culturas ajenas difundidas

12 Con acentuación en las capas o grupos dependientes de retribuciones económicas provenientes del salario estatal, la Seguridad Social, las remesas del exterior, que en su perceptiva, condicionan su mejoramiento económico en el Estado. 
(RAMONET, 2016) interesadas y atemperadas para influenciar en la involución de la conciencia ciudadana solidaria del socialismo. ${ }^{13}$

Ante tal estado de cosas, hoy más que nunca, las acciones estatales encaminadas a transformar la economía y sus relaciones, están obligadas a transitar por la cooperativa, su autogestión y responsabilidad. Ello implica transformar las concepciones estatistas y economicistas sobre el cooperativismo para instituir y aplicar un sistema de educación cooperativa capaz (social, previa y permanente); ${ }^{14}$ así como desechar las concepciones jurídicas actuales sobre el fenómeno cooperativo y los modelos jurídicos existentes, mediante atinada modificación constitucional que generalice el derecho al asociacionismo cooperativo y la promulgación de una Norma General de Cooperativas, adecuada a su naturaleza social. ${ }^{15}$

13 El ciudadano cubano de a pie se enfrenta a su compleja realidad existencial cotidiana, las prestaciones sociales y paradigmáticas de educación, salud, trabajo y otras son habituales y no siempre satisfactorias; mientras los medios masivos de comunicación, las TIC, el intercambio personal, profesional y de otros medios, transmiten culturas burguesas privilegiando la difusión edulcorada de su modo de vida material, actuando cual criterio de medida de las ventajas de la realidad virtual, percibida sobre la realidad existencial vivida.

14 Concebido en tres escenarios:

-EDUCACIÓN SOCIAL: incluyendo temas cooperativos en los programas educativos generales de los niveles de enseñanza secundarios, técnicos, superiores y en los diversos medios de difusión.

-EDUCACIÓN PREVIA: instruyendo en los principios, valores y responsabilidad cooperativa, cual requisito sustantivo a exigir para el aspirante a ingresar a una cooperativa.

-EDUCACIÓN PERMANENTE: sistematizar el conocimiento, la educación y desarrollo de la educación y cultura cooperativa; de valores, tecnología y especialización en programas cooperativos y técnicos de niveles medio y superior.

15 Modificación que generalice el derecho al asociacionismo cooperativo, conceptúe y dote de contenido a la figura jurídica cooperativa, posibilitando la promulgación de la norma general cooperativa coherente y capaz, acorde los elementos básicos siguientes:

- CONCEPTO: reglar a la cooperativa como sociedad de personas que mediante una empresa con fines económico-sociales sin ánimo de lucro, que realizan su actividad cooperativizada en beneficio de sus socios y la comunidad.

- CONSTITUCIÓN: componentes económicos, sociales y jurídicos que la dotan de seguridad jurídica y responsabilidad socio económica y patrimonial.

- Los socios: personas que la integran, sus relaciones y responsabilidades internas y externas.

—ÓRganos sociales: exigencias organizacionales, estructurales, de funcionamiento y relacionales.

—RÉGIMEN ECONÓMICO: precisiones económico patrimoniales para la seguridad jurídica de la cooperativa, socios y terceros; capital social: aportes, certificados; retribuciones: anticipo, retorno, reintegro; el acto cooperativo; responsabilidades.

- CONTABILIDAD Y REGISTRO: obligatoriedad de brindar juicio cierto de la situación financiera y gestión de la actuación social y económico patrimonial. 
La conformación de la voluntad política, para zanjar ambos asuntos del fenómeno cooperativo en Cuba, exige la reflexión dialéctica materialista sobre su esencia y de las condiciones objetivas y subjetivas en que se desarrolla el proyecto socialista cubano hoy, como proceder obligado para arribar a la apropiada conjunción de cultura cooperativa con producción legal; ambas propulsoras de la institución cooperativa y su expresión jurídica como instrumento del cambio y vigorización de relaciones sociales cooperativas y de la sociedad en general.

Donde la voluntad política del Estado se fusione, en democracia, con los intereses y necesidades individuales y sociales para determinar los fines sociales y económicos del país, equilibrando la educación y cultura cooperativa con las exigencias socio jurídicas de la norma, para constituir un claro proceso de comunicación y aprendizaje entre el Estado decisor, aplicador y los sujetos destinatarios - ciudadanos- mediante la imprescindible sistematicidad, racionalidad lingüística, coherencia interna y externa y alto nivel técnico, cual proceder garante de la vigencia de una norma justa, válida y eficaz, que redunde en perfeccionamiento de la sociedad socialista, acompañando al fuerte proceso de educación cooperativa, a su vez consolidado en el Derecho Cooperativo Cubano.

\section{Consideraciones finales}

Si hasta la fecha, en Cuba, los cambios estructurales y organizativos ocurridos en el ámbito empresarial y social, no necesariamente determinan interiorización en los individuos que signifiquen cambios de actuación; y, las motivaciones del accionar estatal obedecen, por lo general, a medidas centralizadas coyunturales de implantación de modelos en la base económica, ${ }^{16}$ con fuerte componente del modelo político tendente a lo administrativo patrimonial, hoy esta cuestión se ha visto superada por la realidad y la necesidad, siendo imperativo para que

—SOluCión DE CONflictos: Intra y extraorganización; clases; vías de solución; ejecutividad de las decisiones, los recursos.

-ORganizACIÓN SOCIAL: de economías y de representatividad social cooperativas; integración, sostenimiento; proyección hacia la comunidad.

-RELACIONES COOPERATIVA-ESTADO: colaboración; funciones reguladoras, fiscalizadoras, de control; calificación y descalificación; impugnaciones.

-TRÁnsito legISLATIVO: Ordenado, transparente, seguro y garante.

16 Cualquier modelo organizativo de una actividad económica no puede ser identificado como cooperativa; solo lo es aquella que integre, al término inscrito en la norma, los elementos básicos que la identifican cual sociedad de persona sui géneris. 
esos cambios sean sustantivos y estructurales e influyan positivamente en la conciencia de los ciudadanos y la sociedad; ello significa que en las normativas que los rigen se consideren y perfilen, de conjunto, los intereses individuales, los sociales y los estatales, siendo imprescindible entonces fijar el cambio con la suficiente coherencia y seguridad jurídica progresiva, no solo económicos estructurales, estableciendo capaces procedimientos de tránsito adecuados.

Si las cooperativas son capaces de dotar de riquezas materiales y espirituales, de cultura a los hombres y son portadoras de una naturaleza socialista avenida con la esencia humana, en el socialismo para el siglo XXI deben constituir sus formas societarias insignes, siendo responsabilidad del estado su promoción y fomento.

Ello es, pues las cooperativas son diferentes en naturaleza, contenido y fines, a las entidades públicas, privadas, individuales o sociales. Constituyen empresas con margen y garantía de expansión, capaces de operar en los diferentes sectores de cualquier economía capitalista, satisfaciendo aspiraciones y necesidades socioeconómicas, reflejadas con efectos benéficos en la comunidad y las naciones; en el socialismo son formas de inestimable valor y perspectivas, en tanto es su sociedad natural, contribuyendo a crear riquezas materiales y espirituales, conciencia social socialista, democrática y responsabilidad personal y colectiva.

En Cuba hoy - pese a la tendencia cooperativa oficial, la realidad contextual y la dispersión y carencias de sus normas vinculantes-, es palpable la existencia de un proceder cooperativo que da origen al ambiente cooperativo nacional, requerido de transformación.

Así, las perspectivas del asunto cooperativo cubano residen en completar los ciclos iniciados por los accionares estatales al constituirlas, de manera que logren desempeñarse cuales auténticas sociedades de personas insignias del socialismo: acometiendo un fuerte proceso de educación cooperativo; y construyendo el Derecho Cooperativo totalizador, que proyecte su naturaleza social asociativa.

\section{Bibliografía}

1. Alianza Cooperativa Internacional (ACI): Declaración sobre la IdenTIDAd CoOperativa, Manchester, 1995. Recuperado de http://www. elhogarobrero1905.org.ar.

2. Asamblea General de la ONU: Resolución no. 49/155, de 23 de diciembre de 1994.

3. FERnÁNDEZ, J. (1999): "Tras las pistas de la Revolución en cuarenta años de Derecho», Revista Temas, no. 18, La Habana, pp. 110-111. 
4. Cabrera, O.: El Programa de la Joven Cuba, Ed. Ciencias Sociales, La Habana, 1977.

5. Castro, F.: La Historia me Absolverá, Ediciones Políticas, La Habana, 1969.

6. Engels, F.: El problema campesino en Francia, Obras Escogidas, Ed. Progreso, Moscú 1982.

7. FeRnÁndez, A.: «El fenómeno cooperativo y el modelo jurídico nacional. Propuesta para la nueva base jurídica del cooperativismo en Cuba». Tesis Doctoral en Ciencias Jurídicas, La Habana, 2005.

8. FernÁndez, A.: «Neoliberalismo y Derecho. Una visión desde las Cooperativas», en Lecturas en pro del Cooperativismo, Ed. Universo Sur, Cienfuegos, 2006.

9. Figueroa, V.: «La transición al socialismo y el derrumbe del socialismo de Estado», en Colectivo de Autores: El derrumbe del modelo eurosoviético, Ed. Félix Varela, La Habana, 1994.

10. Marx, C.: Obras escogidas, t. II, Ed. Progreso, Moscú, 1980.

11. NARANJo, C.: Visión general sobre el marco jurídico del cooperativismo ecuatoriano, 2003, recuperado de http://www.aciamericas.coop.

12. Piñelro, C.: Cooperativas y Socialismo. Una mirada desde Cuba, Ed. Caminos, La Habana, 2011.

13. Piñeiro, $C .:$ «Visiones sobre el Socialismo que guían los cambios actuales en Cuba», en Revista Temas, abril-junio de 2012, pp. 46-55.

14. VI Congreso del Partido Comunista de Cuba: Lineamientos del Partido Comunista de Cuba para la Sociedad y el Estado, La Habana, 2011.

\section{Legislación}

1. Ley No. 95, «Ley de Cooperativas de Producción Agropecuaria y de Créditos y Servicios», de 29 de noviembre de 2002.

2. Ley Decreto No. 1577 de 4 de agosto de 1954.

3. DeCReto-Ley No. 305, de «De las cooperativas no agropecuarias», Gaceta Oficial No. 053 Extraordinaria de 11 de diciembre de 2012.

4. Resolución 574 del Ministerio de la Agricultura, «Reglamento General de las Unidades Básicas de Producción Cooperativa», Gaceta Oficial No. 037 Extraordinaria de 11 de septiembre de 2012. 


\section{Derechos de autor}

La revista Deusto Estudios Cooperativos es una revista de acceso abierto lo que significa que es de libre acceso en su integridad inmediatamente después de la publicación de cada número. Se permite su lectura, la búsqueda, descarga, distribución y reutilización legal en cualquier tipo de soporte sólo para fines no comerciales y según lo previsto por la ley; sin la previa autorización de la Editorial (Universidad de Deusto) o el autor, siempre que la obra original sea debidamente citada (número, año, páginas y DOI si procede) y cualquier cambio en el original esté claramente indicado.

\section{Copyright}

The Deusto Journal of Cooperative Studies is an Open Access journal which means that it is free for full and immediate access, reading, search, download, distribution, and lawful reuse in any medium only for non-commercial purposes, without prior permission from the Publisher or the author; provided the original work is properly cited and any changes to the original are clearly indicated. 